\title{
SUBALTERNIDADE, TRANSCULTURAÇÃO E OUTROS DEMÔNIOS
}

\author{
Lourdes de Fátima Moraes de Sousa ${ }^{1}$
}

RESUMO: O presente trabalho insere-se no debate das características da literatura contemporânea latino-americana e seu vínculo com os aspectos sociais da região. Seu objetivo principal é analisar a relação entre a transculturação que aparece no âmbito literário e a formação das classes sociais na América Latina, a partir da obra do autor colombiano Gabriel Garcia Márquez. Para tanto, por meio do livro Del Amor y Otros Demonios, são assinaladas as intersecções entre o desenvolvimento cultural da classe subalterna e da classe dominante no período colonial e as estruturas de classes que acompanham tal desenvolvimento. $\mathrm{O}$ materialismo histórico e dialético é proposto como corpo teórico, uma vez que permite analisar na literatura a realidade histórica subcontinental e os aspectos universais da civilização capitalista, tais como as classes sociais, a exploração da força de trabalho e a acumulação de capital.

PALAVRAS-CHAVE: Transculturação; Literatura; Classes sociais; América Latina.

RESUMEN: El presente trabajo se inserta en el debate de las características de la literatura contemporánea latinoamericana y su vínculo con los aspectos sociales de la región. Su objetivo principal es analizar la relación entre la transculturación que aparece en el ámbito literario y la formación de las clases sociales en América Latina, a partir de la obra del autor colombiano Gabriel García Márquez. Para ello, a través del libro Del Amor y Otros Demonios, se señalan las intersecciones entre el desarrollo cultural de la clase subalterna y de la clase dominante en el período colonial y las estructuras de clases que acompañan tal desarrollo. El materialismo histórico y dialéctico es propuesto como cuerpo teórico, ya que éste permite analizar en la literatura la realidad histórica subcontinental y los aspectos universales de la civilización capitalista, tales como las clases sociales, la explotación de la fuerza de trabajo y la acumulación de capital.

PALABRAS CLAVE: Transculturación; Literatura; Clases sociales; América Latina.

\section{INTRODUÇÃO}

A cultura enquanto parte constitutiva e não mero reflexo das relações sociais, políticas e econômicas articula-se com a produção do gênero humano manifestando sua singularidade e espaços geográficos concretos, ao mesmo tempo em que incorpora outros elementos presentes em escala universal.

A idiossincrasia da literatura latino-americana é então elemento cultural expressivo e expressado da formação histórica particular da América Latina, desde a sua constituição subcontinental enquanto parte integrada e subordinada ao sistema capitalista em âmbito mundial.

Como outros aspectos sociais da constituição da América Latina, a literatura subcontinental é construída em sua totalidade pelo particular e universal - uma expressão

\footnotetext{
${ }^{1}$ Doutoranda em Literatura - Dinter UFAM/UnB, E-mail: loumoraes@gmail.com 
cultural política e econômica que acompanha o movimento desigual e combinado do devir histórico das sociedades latino-americanas que se integraram ao sistema capitalista a partir de formas pré-capitalistas das quais a formação das classes sociais não pôde escapar da forte marca cultural empregada pelo processo colonial.

Isso pressupõe abordar a literatura latino-americana vinculada em seus múltiplos aspectos e, independentemente da aparência que adquire, como expressão fenomenológica de uma assimilação social violenta dos povos de diversas nações que formaram o subcontinente. Por isso, Alfredo Bosi aponta que "à primeira vista, a cultura letrada parece repetir, sem alternativa, o modelo europeu; mas, posta em situação, em face do índio, ela é estimulada, para não dizer constrangida, a inventar" (1992, p. 31).

É evidente que o apontamento de Bosi também é verdadeiro para o constrangimento da cultura europeia frente ao negro escravo. A dialética que, portanto, acompanha a história das classes sociais na América Latina a partir do movimento de permanência e ruptura da formação primitiva da classe dominante e da classe subalterna, isto é, a essência da colonização, está presente também na produção literária latino-americana.

Assim, a colonização é a unidade dos contrários, pois dela surgem classes sociais antagônicas concomitantemente unificadas pelos elementos culturais inerentes ao empreendimento colonial. Por essa razão, a colonização latino-americana é também o ponto de partida para compreender a cultura de um modo geral e especificamente a literatura, não como mera transposição civilizatória europeia, mas como uma transculturação que pressupõe conflito estético, social e político. A obra de Gabriel Garcia Márquez, especificamente Del Amor y Otros Demonios, publicada em 1994, singulariza o processo.

As ideias apresentadas neste texto correspondem à tentativa de estudar, por meio da obra de um dos principais autores contemporâneos da América Latina - Gabriel Garcia Márquez -, a relação entre uma narrativa transcultural e a exposição literária de uma das categorias da formação econômico-social latino-americana: as classes sociais e suas aproximações em diversas determinações com a formação econômico-social da América Latina, ou seja, o tempo histórico narrativo da obra literária e o tempo histórico objetivo do processo colonial; a localização social e cultural dos personagens e as características das classes sociais na Hispanoamérica; e a relação entre os grupos étnicos a partir de seu desenraizamento cultural original e a formação de uma nova cultura - uma transculturação, no intuito de verificar em quais sentidos narrativos isso altera ou não as estruturas formais da sociedade que emerge da colonização. 
O movimento de análise leva em consideração as características básicas da obra no seu contexto histórico de publicação, seus personagens e o cenário narrativo, assimilando-se à metodologia analítica literária explicitada por Edward W. Said. Isto é:

Os dados a serem observados são o estilo, as figuras de retórica, o cenário, os esquemas narrativos, as circunstâncias históricas e sociais, e não a correção da representação, nem sua fidelidade a algum grande original (SAID, 2008, p. 51).

Dessa forma, é necessária a consolidação de uma base teórico-metodológica que permita a construção de resultados relevantes para a compreensão de como na obra, por meio da transculturação literária, é potencialmente explicitada a formação das classes sociais na América Latina.

\section{O AUTOR}

Gabriel Garcia Márquez, também chamado carinhosamente de Gabo, nasceu no dia 6 de março de 1927, em Aracataca, Colômbia. Foi jornalista, editor e um dos escritores mais importantes do século XX, admirado e traduzido no mundo inteiro. Teve mais de 40 milhões de livros vendidos e traduzidos em dezenas de idiomas.

Como jornalista, passou por vários jornais na função de correspondente internacional na Europa e em Nova York. A obra Del Amor y Otros Demonios, apresentada neste artigo, inclusive, surgiu a partir de um trabalho de reportagem delegado a Márquez.

Entre seus romances e contos, escreveu "Relato de um Náufrago", em 1955, e "O Amor nos Tempos do Cólera", em 1985. Recebeu o Prêmio Esso de novela por "Má Hora" e, em 1971, o prêmio de Doutor Honoris Causa da Universidade Colúmbia, em Nova Iorque. Foi o primeiro colombiano a receber o Nobel da Literatura em 1982, pelo conjunto de sua obra, que inclui, entre outros, "Crônica de uma Morte Anunciada", “ Ninguém Escreve ao Coronel”, “O Outono do Patriarca", "Doze Contos Peregrinos" e "A Incrível História de Cândida Erêndida e sua Avó Desalmada".

Em "Cem Anos de Solidão", seu livro mais famoso, publicado em 1967, Márquez narra a estória de Macondo, uma cidade fictícia, da sua fundação até o seu desaparecimento. A obra utiliza-se de recursos do realismo fantástico e apresenta temas complexos, como revoluções, incesto, corrupção e até loucura. O livro é tido como uma obra prima do autor e da literatura moderna no continente latino-americano. O realismo fantástico estará presente em outros títulos do autor.

Gabriel García Márquez faleceu no dia 17 de abril de 2014, em Cidade do México. 


\title{
DEL AMOR Y OTROS DEMÔNIOS
}

A história de Del Amor y Otros Demonios surge quando Gabriel García Márquez, então jornalista iniciante, aos 22 anos, fica encarregado de uma reportagem em Cartagena, Colômbia, para cobrir a remoção das criptas funerárias do convento de Santa Clara, há um século convertido em hospital e que seria vendido para a construção de um hotel de cinco estrelas. Para Márquez é sugerido que seja feita uma matéria sobre a transformação de usos do local.

Durante a abertura de uma das criptas, Márquez depara-se caixão em que há uma ossada e cabelos de cerca de 20 metros.

\begin{abstract}
No terceiro nicho do altar-mor, do lado do Evangelho, é que estava a notícia. A lápide saltou aos pedaços ao primeiro golpe de picareta, e uma cabeleira viva, cor de cobre intensa, se espalhou para fora da cripta. O meste-de-obras quis retirá-la inteira, com a ajuda de operários, e quanto mais a puxavam, mais comprida e abundante parecia, até que saíram os últimos fios, ainda presos a um crânio de menina. (MÁRQUEZ, 1994, p. 11)
\end{abstract}

Aquela visão faz com que ele se lembre da lenda que sua avó contava, sobre uma marquesinha do Caribe considerada milagrosa e que possuía uma cabeleira tão grande como a cauda de um vestido de noiva.

A partir daí, surge Del Amor Y Otros Demonios e Márquez elabora a história da menina Sierva María de Todos los Ángeles, que se passaria há duzentos anos, durante o vice-reinado na Colômbia, quando esta ainda era colônia espanhola. O livro encerra amor, sortilégios e morte.

Sierva María de Todos los Ángeles, filha única do Marquês de Casalduero, é mordida por um cachorro com raiva, durante um passeio à feira com uma empregada mulata, para comprar enfeites para sua festa de doze anos. Rejeitada pelos pais desde pequena, Sierva María havia sido criada entre os escravos.

Depois do incidente, o pai de Sierva começa a lhe dar mais atenção. Os sintomas da mordida são confundidos com alguma espécie de possessão demoníaca. Recorre-se, então, a curandeiros, feiticeiros, bruxas, ações em busca de retirar o diabo do seu corpo.

Quando a notícia do que está acontecendo com a menina chega aos ouvidos da Igreja, o Marquês é pressionado a deixar a filha em um convento, para ser cuidada pelos obreiros de Deus. A criança é encarcerada e conhece o padre Cayetano Delaura, convocado para tratar do caso, mas os dois se apaixonam e tentam manter secreto o sentimento. Descobertos, Cayetano é impedido de ver a garota, posto à disposição do Santo Ofício e condenado em julgamento em praça pública. 
Sierva María de Todos los Ángeles morre sozinha em sua cela.

\section{TRANSCULTURAÇÃO E SUBALTERNIDADE E OUTROS DEMÔNIOS}

É consolidado na área literária o trabalho de Márquez como transcultural e, sob essa perspectiva, o autor é recorrentemente analisado. No entanto, nos parece relevante questionar se no processo de transculturação da obra de Gabriel Garcia Márquez também não estaria presente uma narrativa implícita da formação das classes sociais na América Latina.

Sob essa perspectiva, não seria possível, então, pensar um processo de transculturação sem considerar as bases materiais advindas das práticas sociais e, ao condensar em si uma dialética de natureza própria enquanto prática social, a literatura poderia, por meio da narrativa transcultural, ir além de uma perspectiva culturalista e explicitar os interesses de classes sociais antagônicas, mantendo a autonomia relativa da própria literatura.

O referencial teórico que norteia o presente trabalho é o materialismo histórico e dialético, a considerar que essa base epistemológica compreende a realidade como síntese de múltiplas determinações concretas em movimento, isto é, por meio do princípio da contradição (MARX, 2013, p. 54).

É a partir das elaborações de Marx e Engels (2007) que este trabalho assimila o conceito de luta entre classes sociais, como força motriz de todo desenvolvimento cultural presente na história humana.

No âmbito literário, isso pressupõe compreender, tal como sugere Raymond Willians (2000, p. 64-65), a literatura como uma contradição que guarda concomitantemente em si uma perspectiva do desenvolvimento social capitalista, portanto uma forma burguesa de controle e especialização de uma prática social, mas também a busca da sensibilidade e da criatividade frente à mecanização das práticas sociais do capitalismo.

Assim, como parte do arcabouço teórico que elegemos, temos como ponto de partida que a literatura moderna é em si e para si intrinsecamente vinculada à estrutura do modo de produção capitalista, ou seja, às classes sociais e ao mesmo tempo expressa a negação e a rejeição ao estranhamento advindo desse modelo societário.

Por outro lado, os pressupostos da sociedade de classes na literatura exigem mediações históricas e culturais que formam a particularidade do desenvolvimento social de cada região. Por esse motivo, assimilamos junto com a categoria "classes sociais" o conceito de transculturação para investigarmos a idiossincrasia literária subcontinental que busca sintetizar a formação histórico-cultural das classes sociais na América Latina. 
O conceito de transculturação nasce e se desenvolve inicialmente na antropologia cubana por meio do pensamento de Fernando Ortiz. Em sua gênese, esse conceito fora gestado como contraponto à ideia hegemônica de aculturação, ou seja, como a negação de que as relações sociais transformam-se em simples imposição e assimilação de uma cultura sobre a outra. Na definição de Ortiz (1983, p. 91), a transculturação é o desenraizamento de uma cultura anterior em simultaneidade à criação de novos fenômenos culturais, em um processo de superação por assimilação.

Durante a década de 1980, o caráter genuinamente dialético internalizado no conceito de transculturação expandiu da antropologia para tornar-se base analítica das expressões artísticas latino-americanas, com destaque para a crítica literária formulada pelo uruguaio Àngel Rama, o qual incorporou o conceito como ferramenta de análise da literatura.

Ao trazer o conceito transcultural para o âmbito literário, Rama (2008, p. 47) adicionou como mediação o critério de seletividade, no qual os sujeitos ativos da criação literária na América Latina selecionam os pontos a manter na cultura endógena e a assimilar da cultura exógena. Para autor destacam-se então três critérios seletivos na narrativa transcultural:

a) a língua;

b) a estrutura literária e

c) a cosmovisão.

De acordo com Rama, a partir da década de 1940, o movimento literário latinoamericano buscou romper com a dicotomia entre a norma culta do narrador e a linguagem regional das personagens, na tentativa de construir unidade no texto literário narrado desde dentro e não mais como uma narração estrangeira.

Em consonância com a unidade textual por meio da língua, destaca-se ainda a estrutura literária transcultural que se submete à estrutura social que inspira o texto, de modo que as características da comunicação regional explicitam-se na obra, tal como a presença do monólogo em diversas obras transculturalistas.

Sobre a cosmovisão, Rama caracteriza que essa é parte da desculturação do antigo estilo literário regionalista, que uma vez submetido ao estilo da narrativa sociológica modernista e positivista da burguesia europeia, juntamente com o estilo culto narrador, era um elemento de cisão entre a narrativa e as personagens. Dessa maneira, a literatura latino-americana do período pós-Segunda Guerra Mundial substituiu o racionalismo eurocêntrico pelo caráter místico das culturais locais como ponto de partida das narrativas literárias.

A própria transculturação literária traz, então, em seu interior, outra categoria central do marxismo - a dialética, pois ao construir uma narrativa que tem por base uma realidade em 
movimento e que se desenvolve mediante interesses antagônicos de classes sociais constituídas, a transculturação não é senão o:

(...) conflito implícito numa literatura produzida por sociedades internamente heterogêneas, inclusive multinacionais dentro dos limites de cada país, ainda marcadas por um processo de conquista e uma dominação colonial e neocolonial que apenas uma vez, em Cuba, se pôde romper de maneira definitiva. Uma literatura produzida por sociedades assim constituídas não pode deixar de refletir e/ou reproduzir os múltiplos níveis de um conflito que impregna a totalidade de sua estrutura e sua dinâmica (CORNEJO POLAR, 2000, p. 21).

Nesse sentido, a análise da literatura da América Latina implica no eixo teóricometodológico que parte de elementos universais do processo civilizatório capitalista, como a exploração entre classes, o devir conflituoso das relações sociais, etc., para compreender a combinação e desigualdade de tais elementos na formação econômico-social latino-americana. Isso porque as sociedades subcontinentais têm por essência não apenas a exploração, mas a opressão colonial até o presente momento em vigência e que hegemonicamente se manifesta nas mais diversas expressões artísticas ao mesmo tempo em que serve de base material para uma crítica literária comprometida com as camadas populares. Por essa razão são pertinentes as indagações sugeridas por Antônio Cândido:

qual a influência exercida pelo meio social sobre a obra de arte? Digamos que ela deve ser imediatamente completada por outra: qual a influência exercida pela obra de arte sobre o meio? Assim poderemos chegar mais perto de uma interpretação dialética, superando o caráter mecanicista das que geralmente predominam. Algumas das tendências mais vivas da estética moderna estão empenhadas em estudar como a obra de arte plasma o meio, cria o seu público e as suas vias de penetração, agindo em sentido inverso ao das influências externas (CANDIDO, 2011, p. 28).

Desse modo, a perspectiva de aproximação para investigação do objeto escolhido foi a dialética materialista no sentido de compreender a combinação entre aspectos culturais e a relação social de produção presentes em Del Amor y Otros Demonios.

$\mathrm{Na}$ condição de um dos principais escritores contemporâneos da América Latina, Gabriel Garcia Márquez relaciona-se com a região a partir da incorporação em suas obras da formação histórica latino-americana como cenário delimitado no qual surgem seus personagens.

Partindo de um recorte temporal, geográfico, e, sobretudo, político em sentido amplo, Garcia Márquez reconstitui por meio de suas estórias os aspectos mais uterinos da história latino-americana, tais como os conflitos sociais e culturais. Todavia, o faz desde uma angulação endógena, isto é, tendo como central as perspectivas e não apenas as caracterizações das 
personagens, o que afasta uma narrativa distanciada de um tipo de realismo eurocêntrico. Esse sentido fica nítido em sua obra Del Amor y Otros Demonios.

Del Amor y Otros Demonios foi produzido por Gabriel Garcia Márquez no ano de 1994 e pode ser considerada uma produção na qual está consolidada a perspectiva do autor como parte de uma literatura nacional e popular, perspectiva esta que se iniciou em meados da década de 1950 com a publicação da obra Lahojarasca (COLORADO, 2012, p.111-113).

Ambientado na Colômbia do século XVIII, portanto na fase decadente do comércio de escravos pela rota de Cartagena de las Índias, Del Amor y Otros Demonios traz pela primeira vez nos escritos do autor a cultura negra como centro da sua narrativa e um permanente confronto desta com a imposição cultural europeia, cuja difusão é responsabilidade da Igreja.

De acordo com Margareth M. Olsen (2002, p.1067), em Del Amor y Otros Demonios, Gabriel Garcia Márquez solapa a colonialidade e a modernidade ao evidenciar a atuação dos setores subalternos como universo construtor sob o qual se movimenta todo o enredo narrativo:

Na construção da história nacional, García Márquez localiza a autoridade não em um texto escrito, mas no artefato e na memória oral. As vozes marginalizadas recebem prioridades dentro do texto de recriação colonial e no contexto contemporâneo que supostamente motiva a origem do romance. Ao justapor essas vozes com a Inquisição que as silenciou no discurso oficial, García Márquez se compromete em minar a retórica da modernidade (OLSEN, 2002, p. 1067).

Embora seja importante incorporar este apontamento proposto por Olsen, é preciso localizá-lo nos próprios escritos de Gabriel Garcia Márquez para além de uma compreensão exclusivamente culturalista, tal como se a cultura emanada das personagens fosse autônoma frente ao lugar em que cada uma ocupa na divisão social do trabalho, ou seja, a classe social a que pertence.

Ao entrar no espaço colonial como cenário histórico, Del Amor y Otros Demonios explicita também a relação entre as classes sociais em sua forma primeira na América Latina, isto é, por meio das relações pré-capitalistas transportadas de outros modos de produção como locomotiva do empreendimento colonial hispânico voltado ao mercado mundial (QUIJANO, 2005, p. 107).

Para além do que se apresenta a obra em sua perspectiva ficcional, a narrativa, que tem como pano de fundo a relação de uma marquesa com o universo africano e a demonização da cultura afro pelo expediente católico, não se encerra somente nos aspetos culturais que aparecem explicitamente na obra, mas também na delimitação de classe que acompanha cada personagem. 
Ao aparecerem como pilar sobre o qual se edifica e também se desmorona a sociedade do século XVIII, os escravos são apresentados na obra como eixo social que proporciona sentido ao mundo colonial, isto é, membros da única classe produtiva no colonialismo.

Por outro lado, a aristocracia representada, sobretudo, pelas personagens do marquês de Casalduro e de sua esposa Bernarda Cabreira, uma contrabandista de escravos sem título de nobreza, é indicação das formas primitivas da burguesia latino-americana. Uma elite que assentada na grande propriedade da terra importou os costumes referendados socialmente da Europa, ao mesmo tempo em que organicamente vinculada ao escravismo, não pôde escapar das práticas sociais dos grupos subalternos.

Foi Bernarda quem descobriu que o bom negócio não eram os escravos, e sim a farinha, embora o grande negócio, na realidade, fosse o seu inacreditável poder de persuasão. Com uma só licença para importar mil escravos em quatro anos e três barris de farinha por um escravo, deu a tacada de sua vida: vendeu os mil negros acertados, mas em vez de três mil barris de farinha importou doze mil. (MARQUEZ, p 67)

Essa relação fica evidente na própria formação e desenvolvimento da personagem central, a marquesa Sierva María de Todos los Ángeles, adolescente nobre, cuja educação foi relegada aos escravos e que termina por adquirir costumes negros, obrigando posteriormente sua família a tentar "resgatá-la" para a cultura cristã e para os padrões sociais europeus.

Criada no pátio dos escravos, Sierva María aprendeu a dançar antes de falar, aprendeu três línguas africanas ao mesmo tempo, a beber sangue de galo em jejum e a esgueirar-se entre os cristãos sem ser vista nem pressentida, como um ser imaterial. (MARQUEZ, p 66)

A relevância da obra Del Amor y Otros Demonios, aqui, também se dá nesse sentido, pois nela Gabriel Garcia Márquez localiza a transculturação nas bases materiais sobre a quais se alicerçaram o colonialismo, sendo sua narrativa uma negação indireta da perspectiva que autonomiza a cultura como desvinculada das relações entre as classes sociais. Compreender como se combinam os aspectos da formação das classes sociais na América Latina e o conceito de transculturação e subalternidade na obra de Márquez é a busca da verificação da dialética como eixo antagônico ao determinismo mecânico de uma perspectiva sociológica e também da autonomização cultural frente às relações sociais de produção. 


\section{CONSIDERAÇÕES FINAIS}

Sob a nossa análise, no livro Del Amor y Outros Demonios, Gabriel Garcia Márquez não apenas incorpora o conceito de transculturação, como a partir dele expõem os elementos de formação das classes sociais em uma das fases decadentes do período colonial. Nesse sentido, hipoteticamente, a abordagem do livro estaria além de uma narrativa circunscrita ao campo cultural em seu sentido stricto sensu, mas apresenta também elementos políticos e sociais próprios da constituição das classes dominantes e subalternas latino-americanas.

Novos estudos sobre o romance Del Amor y Otros Demonios poderão se desdobrar a partir da verificação de como o singular está implícito no universal, bem como o inverso, e como a dialética constituída entre ambas forma a totalidade da cosmovisão literária.

\section{REFERÊNCIAS}

AGUIAR, F.; RODRIGUES, J. [Orgs.]. Ángel Rama: um transculturador do futuro. Belo Horizonte: Editora UFMG, 2013.

BENJAMIN, W. Magia e técnica, arte e política: ensaios sobre literatura e história da cultura. São Paulo: Brasiliense, 2012.

BOSI, A. Dialética da Colonização. São Paulo: Companhia das Letras, 2002.

CANDIDO, A. Literatura e Sociedade. Rio de Janeiro: Ouro sobre Azul, 2011.

COLORADO, P. A.M. La narrativa de Gabriel García Márquez vista por Ángel Rama y larecepción de su crítica em Colombia. In: Estudios de Literatura Colombiana, N. 30, nerojunio, 2012, ISSN 0123-4412, p. 109-128.

CORRÊA, A. L. dos R. As duas faces das medalhas: dialética aparência e essência em "Teoria do Medalhão" e "O Emplasto". O eixo e a roda, Belo Horizonte, v. 24, n. 2, p. 31-47, 2015.

CUNHA, R. B. Transculturação Narrativa: seu percurso na obra crítica de Ángel Rama. São Paulo: Humanitas Editorial. 2007.

CORNEJO POLAR, A. O condor voa. Literatura e cultura latino-americanas. Belo Horizonte: Editora UFMG, 2000.

EAGLETON, T. A ideia de cultura. São Paulo: UNESP. 2000. 
GÓMEZ, G. R.; FLORES, J. G.; JIMÉNEZ, E. G. Metodología de lainvestigación cualitativa. Málaga: Ediciones Aljibe, 1996.

LUKÁCS, G. "Introdução aos escritos estéticos de Marx e Engels". In: MARX, K; ENGELS, F. Cultura, arte e literatura: textos escolhidos. São Paulo: Expressão Popular, 2010.

MÁRQUEZ, G.G. Del Amor y Otros Demonios. Buenos Aires: Editorial Sudamericana, 1994. MARX, K. Grundisse: manuscritos econômicos de 1857-1858: esboços da crítica da economia política. São Paulo: Boitempo Editorial, 2011.

MARX, K; ENGELS, F. Manifesto Comunista. São Paulo: Boitempo Editoria, 2007.

ORTIZ, F. Contrapuenteo Cubano del tabaco y elazúcar. Cuba: Editorial de cienciassociales, La Habana, 1983.

OLSEN, M.M. La Patología de laafricaníaen Del Amor y OtrosDemonios de García Márquez In: Revista Iberoamericana. Vol. LXVIII, Núm. 201, Octubre-Diciembre 2002, 10671080 .

QUIJANO, A. “Colonialidade do poder, eurocentrismo e América Latina”. In: LANGER, E. [Org.]. A colonialidade do saber: eurocentrismo e ciências sociais. Perspectivas latinoamericanas. Ciudad Autónoma de Buenos Aires, Argentina, setembro 2005. Disponível em <http://bibliotecavirtual.clacso.org.ar/> Acesso em: 2017-06-24.

RAMA, À. Transculturación narrativa en América Latina. Buenos Aires: Ediciones El Andariego, 2008.

RAMA, A. A Cidade das Letras. São Paulo: Brasiliense, 1985.

SAID, E. W. Orientalismo: o oriente como invenção do ocidente. São Paulo: Cia das Letras. 2008.

SPIVAK, G. C. Pode o Subalterno Falar? Belo Horizonte: Editora UFMG, 2010.

TORO, E. A. M. Ángel Rama e Antonio Candido: de um sistema literário para o Brasil à construção de uma literatura para a América Latina. 2014. Dissertação. UFMG.

WILLIAMS, R. Marxismo y Literatura. Barcelona: Ediciones Península, 2000.

Recebido em: 28/02/2018

Aprovado em: 03/04/2018

Publicado em: 01/07/2018 